\title{
Effect of Cold Stress on Photosynthetic Traits, Carbohydrates, Morphology, and Anatomy in Nine Cultivars of Stevia rebaudiana
}

\author{
Shokoofeh Hajihashemi i*, Fariba Noedoost ${ }^{1}$, Jan M. C. Geuns ${ }^{2}$, Ivica Djalovic ${ }^{3}$ and \\ Kadambot H. M. Siddique ${ }^{4,5 *}$ \\ ${ }^{1}$ Plant Biology Department, Faculty of Science, Behbahan Khatam Alanbia University of Technology, Behbahan, Iran, \\ ${ }^{2}$ Laboratory of Functional Biology, KU Leuven, Leuven, Belgium, ${ }^{3}$ Institute of Field and Vegetable Crops, Novi Sad, Serbia, \\ ${ }^{4}$ The UWA Institute of Agriculture, The University of Western Australia, Perth, WA, Australia, ${ }^{5}$ UWA School of Agriculture \\ and Environment, The University of Western Australia, Perth, WA, Australia
}

OPEN ACCESS

Edited by:

William Walter Adams III, University of Colorado Boulder, United States

Reviewed by: Arnd G. Heyer, University of Stuttgart, Germany

Christopher M. Cohu, Phytoremediation and Phytomining Consultants United, LLC., United States

*Correspondence:

Shokoofeh Hajihashemi hajihashemi@bkatu.ac.ir

Kadambot H. M. Siddique kadambot.siddique@uwa.edu.au

Specialty section:

This article was submitted to

Plant Abiotic Stress,

a section of the journal

Frontiers in Plant Science

Received: 08 June 2018 Accepted: 07 September 2018 Published: 28 September 2018

Citation:

Hajihashemi S, Noedoost $F$,

Geuns JMC, Djalovic I and Siddique KHM (2018) Effect of Cold

Stress on Photosynthetic Traits, Carbohydrates, Morphology, and Anatomy in Nine Cultivars

of Stevia rebaudiana.

Front. Plant Sci. 9:1430.

doi: 10.3389/fpls.2018.01430
Stevia rebaudiana Bertoni is a sweet medicinal herb that is cultivated worldwide. This study aimed to identify the genotypic responses and function of nine cultivars of S. rebaudiana (accession numbers 1-9 from the EUSTAS Stevia Gene Bank) to low temperature. Plants were grown in vitro and incubated under controlled conditions at $5^{\circ}$ or $25^{\circ} \mathrm{C}$ for 1 month. Cold stress significantly decreased the maximum quantum yield of photosystem II $\left(F_{v} / F_{m}\right)$ in all cultivars, which was more pronounced in cultivars $5,6,8$, and 9. The efficiency of photosystems I and II ( $\left(\mathrm{Pl}_{\mathrm{ABS}}\right)$ also declined in cold-stressed plants and was accompanied by reductions in net photosynthesis $\left(P_{N}\right)$, intercellular $\mathrm{CO}_{2}\left(\mathrm{C}_{\mathrm{i}}\right)$, water use efficiency (WUE), and chlorophyll $a$, chlorophyll $b$ and carotenoid contents, more so in cultivars $5,6,8$, and 9 . Regardless of the downregulation of photosynthetic capacity, the cold stress increased water-soluble carbohydrates in all cultivars, which was accompanied by an increase in fresh leaf mass and area, more so in cultivars 5, 6, 8, and 9. Furthermore, cold stress increased the stomatal index and density, epidermal cell density, stem diameter, xylem vessel width, phloem tissue width, and number of sclerenchyma in all cultivars. Even though the nine cultivars of S. rebaudiana had lower PSIl efficiencies at low temperatures, the increase in carbohydrates and leaf mass suggests that damage to PSII is not responsible for the reduction in its efficiency.

Keywords: carbohydrate, cold stress, morphology, photosynthesis, stem, Stevia rebaudiana, stomata

\section{INTRODUCTION}

Stevia rebaudina Bertoni is a perennial sweet medicinal herb belonging to the Asteraceae family and native to Paraguay, Brazil, and Argentina with their subtropical climates and mild winters. Stevia leaves contain sweet diterpene glycosides or steviol glycosides (SVglys), which form up to 25\% of the leaf dry mass (Geuns, 2003). Glycosyltransferase enzymes are responsible for glycosylation

Abbreviations: car, carotenoids; $\mathrm{Chl}$, chlorophyll; $\mathrm{C}_{\mathrm{i}}$, intercellular $\mathrm{CO}_{2} ; \mathrm{F}_{\mathrm{m}}$, maximum fluorescence; $\mathrm{F}_{\mathrm{v}}$, variable fluorescence; $\mathrm{F}_{\mathrm{v}} / \mathrm{F}_{\mathrm{m}}$, maximum photochemical efficiency of PSII; $\mathrm{PI}_{\mathrm{ABS}}$, performance index; $\mathrm{P}_{\mathrm{N}}$, net photosynthesis; SVglys, steviol glycosides; WSC, water-soluble carbohydrates; WUE, water use efficiency. 
of the steviol molecule by transferring the glucose moiety to form various SVglys, with different units of D-glucose attached to the steviol ring. Large amounts of SVglys are found within the leaves of S. rebaudiana (Ceunen and Geuns, 2013). Accordingly, a noticeable amount of the carbon generated by photosynthesis is used for SVglys biosynthesis. Stevia cultivation is relatively successful in different regions of the world, though plants may experience cold stress in winter. Cold stress affects the physiological, biochemical, molecular, growth, and developmental processes of plants (Kumar Yadav, 2010). Plant exposure to low temperature during winter results in changes in photosynthetic capacity, plant anatomy, and carbohydrate contents (Ensminger et al., 2006; Cohu et al., 2014; Muller et al., 2014; Adams et al., 2016). Limited research has been undertaken on Stevia in relation to its performance under cold stress (Soufi et al., 2016) and no studies have sought to identify variation in Stevia cultivars in their acclimatory responses during growth in cold seasons.

Photosynthesis is the principal process of capturing light energy to form carbohydrates and is sensitive to low temperature (Adams and Demmig-Adams, 2004; Ensminger et al., 2006; Fan et al., 2015; Stewart et al., 2016). Chlorophyll (Chl) fluorescence is a direct tool for detecting photosystem II (PSII) efficiency, as the ratio of $F_{V}$ to maximal fluorescence emission $\left(F_{V} / F_{m}\right)$ (Logan et al., 2007; Adams et al., 2013, 2014). Although photoinhibition reduces efficiency of photosynthetic electron transport, it can be regarded as a means of protection of the photosynthetic apparatus in response to environmental stress; its key characteristics are a reduction in $\mathrm{Fv} / \mathrm{Fm}$ and dissipation of light energy as heat. Despite the reduction in photosynthetic capacity it is often accompanied by increased sugar accumulation, which is a typical stress response in many plants (Adams et al., 2006, 2013, 2014; Logan et al., 2014). In Vicia minor, a reduction in photosynthetic rate and PSII efficiency in response to low temperature was accompanied by soluble sugar accumulation (Adams et al., 2013, 2014). Characterization of the PI $\mathrm{ABS}_{\text {S }}$ another tool that reflects the efficiency of both PSI and PSII in different conditions (Živčák et al., 2008). Indications of photosynthetic apparatus responses to environmental stress can also be based on variations in intercellular $\mathrm{CO}_{2}$ concentration $\left(C_{i}\right), P_{N}$, or WUE (Adams et al., 2013, 2014; Cohu et al., 2014).

Stomata play an important role in regulating photosynthesis and transpiration. Stomatal density is the number of stomata per unit leaf area, whereas the stomatal index is a function of both the number of stomata and the size of the epidermal cells. Stomatal density and index are ecophysiological parameters that can be affected by environmental factors such as drought, humidity, light, heavy metals, and $\mathrm{CO}_{2}$ concentration (Royer, 2001; Banon et al., 2004; Vezza et al., 2018). Numerous studies have shown that stomatal size, density, and pattern of stomatal distribution in leaves are controlled by long-term high temperatures (Maherali et al., 2002; Franks and Farquhar, 2007; Zheng et al., 2013; Hill et al., 2014; Yan et al., 2017; Wu et al., 2018). Photosynthetic capacity is closely linked to stomatal density (Xu et al., 2016). Wu et al. (2018) reported that warming had a different effect on two cultivars of Syzygium. High temperature significantly decreased stomatal size in $S$. rehderianum and stomatal density in
S. superba. Warming also decreased photosynthesis in S. superba, but had no significant effect on photosynthesis in S. rehderianum (Wu et al., 2018). Wu et al. (2018) reported that a reduction in stomatal density had a negative effect on photosynthesis, while maintaining stomatal conductance and the photosynthetic rate was probably due to a reduction in stomatal size. Accordingly, investigating stomatal responses in the leaves of different Stevia cultivars experiencing low temperature may be important for gas exchange and photosynthetic capacity.

Understanding the changes in plant anatomy in response to cold stress will improve our knowledge of how plants cope with low temperature. Water transport is mainly related to the structure of the xylem vessels in plant stems (Banon et al., 2004). The geographical distribution of the plant may be relevant to the occurrence of narrow stem vessels, which provide high resistance to cavitation from low temperatures during winter. Vessel grouping in the stem protects against cavitation (Psaras and Sofroniou, 2004). Several studies have reported significant increases in the number of phloem cells in leaf veins in response to low temperature, which increased sugar export from leaves to other parts of the plant (Cohu et al., 2014; Muller et al., 2014; Stewart et al., 2016). Furthermore, cold stress can increase leaf thickness and dry mass in some plant species (Adams et al., 2013; Cohu et al., 2014; Stewart et al., 2016).

Different plant cultivars can exhibit different adaptive responses to the same environmental conditions. Indeed, the overall photosynthetic capacity under stress might differ between species or ecotypes and may interact with the severity of the environmental stress. Winter annuals exposed to low temperature exhibited upregulation of photosynthesis, increased carbohydrates, and changes in morphological and anatomical features (Cohu et al., 2014; Muller et al., 2014; Stewart et al., 2016). This study investigated the variation in photosynthetic responses of different Stevia cultivars to low temperature, which could be a valuable resource to illustrate the performance and photoinhibition of different cultivars. We exposed nine Stevia cultivars to cold stress in vitro and measured $\mathrm{F}_{\mathrm{v}} / \mathrm{F}_{\mathrm{m}}, \mathrm{PI}_{\mathrm{ABS}}, \mathrm{C}_{\mathrm{i}}$, $\mathrm{P}_{\mathrm{N}}$, WUE, and Chl $a$, Chl $b$, and carotenoid contents. We also measured WSC and glucose accumulation to characterize any correlation between carbohydrate content and photosynthesis. Changes in the morphology and anatomy of stomata and stems were also studied in cold-stressed Stevia cultivars.

\section{MATERIALS AND METHODS}

\section{Plant Culture and Cold Stress}

Nine cultivars of $S$. rebaudiana were obtained from the EUSTAS Stevia Gene Bank and labeled as accessions 1-9 (Laboratory of Tropical Crop Improvement, Leuven, Belgium; Van den Houwe et al., 2011). Three seedlings per cultivar were cultured in vitro on Murashige and Skoog (1962) medium in a glass jar. At least 20 glass jars containing three seedlings were prepared for each Stevia cultivar. The plants were incubated in a growth chamber set at $25 \pm 1{ }^{\circ} \mathrm{C}$ with a photoperiod of $16 \mathrm{~h}$ under white fluorescent lamps $(150 \mu \mathrm{mol}$ photon $\mathrm{m}^{-2} \mathrm{~s}^{-1}$ ) for 2 months. After 2 months, eight glass jars of 
each cultivar containing three seedlings of similar height, stem number, and leaf size were selected for the cold stress and control treatments. Four of these jars of each cultivar were maintained in a growth chamber set at $25 \pm 1^{\circ} \mathrm{C}$ with a photoperiod of $16 \mathrm{~h}$ under white fluorescent lamps $\left(150 \mu \mathrm{mol}\right.$ photon $\mathrm{m}^{-2}$ $s^{-1}$ ) while the other four jars were exposed to cold stress for 1 month in a growth chamber set at $5 \pm 1^{\circ} \mathrm{C}$ with the same photoperiod regimes. At the end of the cold stress, all plants were moved to a growth chamber set at $25 \pm 1{ }^{\circ} \mathrm{C}$ for $4 \mathrm{~h}$ before undertaking further analysis (photosynthetic efficiency, photosynthetic carbon dioxide uptake, pigment and carbohydrate sampling, and anatomical studies) for a more reliable comparison among treatments and cultivars, with all samples having the same leaf temperature.

\section{Gas Exchange and Fluorescence}

For all treatments, measurements were taken in triplicate on the six youngest fully expanded leaves per plant of four plants from four jars. The measurements were done on these leaves because they had emerged during the treatment. All plants were exposed to light in the growth chamber for about $2 \mathrm{~h}$, before being placed in the dark for at least 30 min prior to obtaining values for $\mathrm{F}_{\mathrm{v}} / \mathrm{F}_{\mathrm{m}}$ and $\mathrm{PI}_{\mathrm{ABS}}$ using a portable chlorophyll fluorometer (Pocket PEA, Hansatech, England). The following equations were used to calculate $\mathrm{F}_{\mathrm{v}} / \mathrm{F}_{\mathrm{m}}$ and $\mathrm{PI}_{\mathrm{ABS}}$ parameters (Živčák et al., 2008):

$$
\begin{aligned}
& \mathrm{F}_{\mathrm{V}} / \mathrm{F}_{\mathrm{M}}=\left(\mathrm{F}_{\mathrm{M}}-\mathrm{F}_{\mathrm{o}}\right) / \mathrm{F}_{\mathrm{M}} \\
& \mathrm{PI}_{\mathrm{ABS}}=\frac{1-\left(\mathrm{F}_{\mathrm{o}} / \mathrm{F}_{\mathrm{M}}\right)}{\mathrm{M}_{\mathrm{o}} / \mathrm{V}_{\mathrm{J}}} \times \frac{\mathrm{F}_{\mathrm{M}}-\mathrm{F}_{\mathrm{o}}}{\mathrm{F}_{\mathrm{o}}} \times \frac{1-\mathrm{V}_{\mathrm{J}}}{\mathrm{V}_{\mathrm{J}}}
\end{aligned}
$$

where $F_{0}$ is fluorescence intensity, $F_{M}$ is maximum fluorescence intensity, $V_{J}$ is relative $F_{V}$, and $M_{0}$ is the initial slope of fluorescence kinetics. Intercellular $\mathrm{CO}_{2}$ concentration $\left(\mathrm{C}_{\mathrm{i}}\right), \mathrm{P}_{\mathrm{N}}$, and WUE were measured using a portable plant photosynthesis meter (KR8700 system; Korea Tech Inc., South Korea). All samples had the same leaf temperature. The six youngest fully expanded leaves per plant were then harvested, as one replicate, for the measurements outlined in the following three sections.

\section{Photosynthetic Pigments}

The Chl $a$, Chl $b$, and carotenoid contents were determined using an extraction in $80 \%(\mathrm{v} / \mathrm{v})$ acetone as per the method of Lichtenthaler and Wellburn (1983).

\section{Water-Soluble Carbohydrates}

Water-soluble carbohydrates (WSC) were determined according to the phenol-sulfuric-acid method (Dubois et al., 1956).

\section{Glucose}

Some of the extract obtained from the phenol-sulfuric-acid method above was used to measure glucose content with a glucose assay kit (Sigma).

\section{Anatomical Studies}

The anatomical characteristics of Stevia stems and leaves were evaluated after 1 month of cold stress. Four stem samples from four plants in different jars of each cultivar were fixed in formalin-acetic acid-alcohol (FAA 1:1:18 v/v). Cross-sections were manually cut, double-stained with carmine and methyl green (Amini Rad and Sonboli, 2008), and then viewed and photographed using a light microscope (Olympus BX51) with an automatic camera at $100 \times$ and $400 \times$ magnifications. Anatomical features-stem diameter $(\mathrm{mm})$, epidermal width $(\mu \mathrm{m})$, dermal width $(\mu \mathrm{m})$, xylematic vessel width $(\mu \mathrm{m})$, number of sclerenchyma per colony, sclerenchyma colony width $(\mu \mathrm{m})$, and phloem tissue width $(\mu \mathrm{m})$-were measured using Image Tools Version 3.0 software. The fresh weight and area of the six youngest fully extended leaves per plant were measured, and the fresh leaf mass per area ( $\mathrm{mg}$ fresh weight $\mathrm{cm}^{-2}$ ), leaf area of six leaves $\left(\mathrm{cm}^{2}\right)$, and fresh mass of six leaves $(\mathrm{mg})$ are reported. For leaf epidermis properties, a colorless nail coating was brushed on the adaxial leaf side of the six youngest fully expanded leaves per plant of each cultivar. The sellotape, with its varnish imprint, was carefully removed from the leaf to obtain epidermal impressions for analysis (Vezza et al., 2018). The number of stomata was measured using an Olympus BX51 microscope at $200 \times$ magnification. The length and width of guard cells were measured at $400 \times$ magnification with Image Tools Version 3.0 software. Stomatal density (SD) and epidermal cell density (ECD) were measured per unit area and used to calculate the stomatal index (SI):

$$
\mathrm{SI}=\mathrm{SD} /(\mathrm{SD}+\mathrm{ECD}) \times 100
$$

\section{Statistical Analyses}

The experiment (e.g., plant culture and treatment) was repeated three times, with a separate analysis conducted for each experiment. Each experiment included the set of four jars with three plants for each treatment and each cultivar. Statistical analysis was performed with SPSS software (version 23). For the parameters of $\mathrm{F}_{\mathrm{v}} / \mathrm{F}_{\mathrm{m}}, \mathrm{PI}_{\mathrm{ABS}}, \mathrm{C}_{\mathrm{i}}, \mathrm{P}_{\mathrm{N}}$, and WUE, the average of the collected data for six leaves per plant was considered as one replicate. The means for $\mathrm{F}_{\mathrm{v}} / \mathrm{F}_{\mathrm{m}}, \mathrm{PI}_{\mathrm{ABS}}, \mathrm{C}_{\mathrm{i}}, \mathrm{P}_{\mathrm{N}}$, and WUE, photosynthetic pigments, WSC and glucose are the average of 12 plants from 12 jars across three experiments. The means of anatomical features are the average of four values from four plants in four jars for each treatment. For leaf biomass per area, the average of six leaves per plant was considered as one replicate, and the means are the average of four individual plants from four jars. The sum of fresh mass and area of six leaves per plant were considered as one replicate and the means are the average of four individual plants from four jars. Significant differences between parameters were determined by two-way ANOVA test. The Duncan's test $(p \leq 0.05)$ was used to compare means.

\section{RESULTS}

The $\mathrm{F}_{\mathrm{v}} / \mathrm{F}_{\mathrm{m}}$ ratio of $S$. rebaudiana declined significantly in all cultivars from about 0.80 in control plants to $0.41-0.69$ in coldstressed plants (Figure 1A), more so in cultivars 5, 6, 8, and 9 (44-47\%) than cultivars 1, 2, 3, 4, and 7 (12-14\%). Cold stress significantly reduced the $\mathrm{PI}_{\mathrm{ABS}}$ value by $50-73 \%$ (Figure 1B). 
A

- $25^{\circ} \mathrm{C} / 5^{\circ} \mathrm{C}$

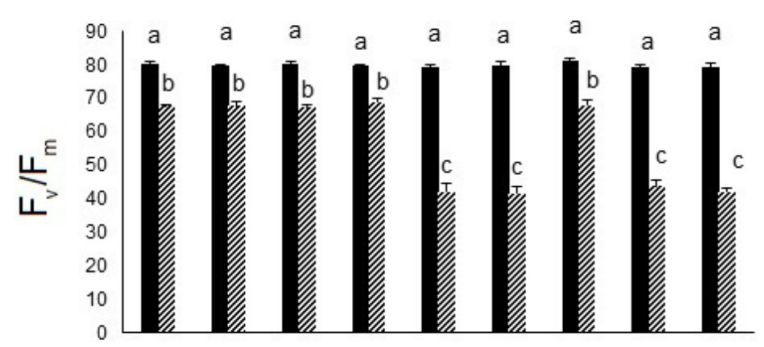

C

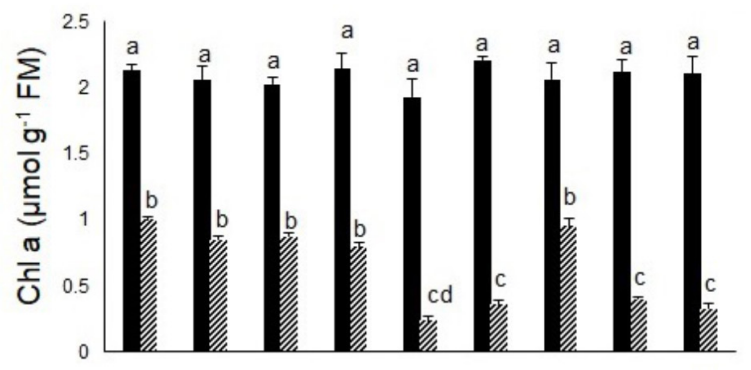

E

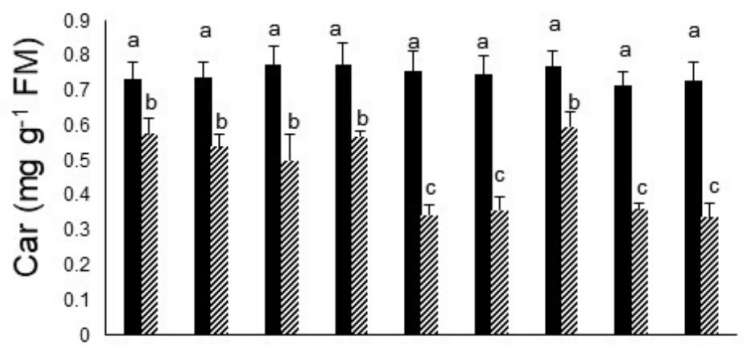

G

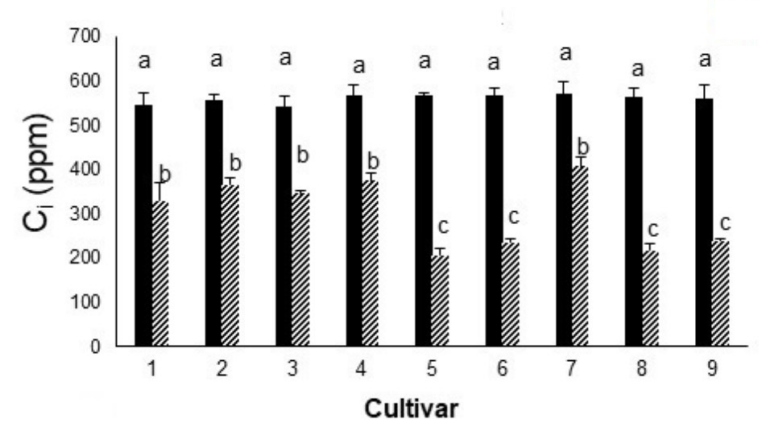

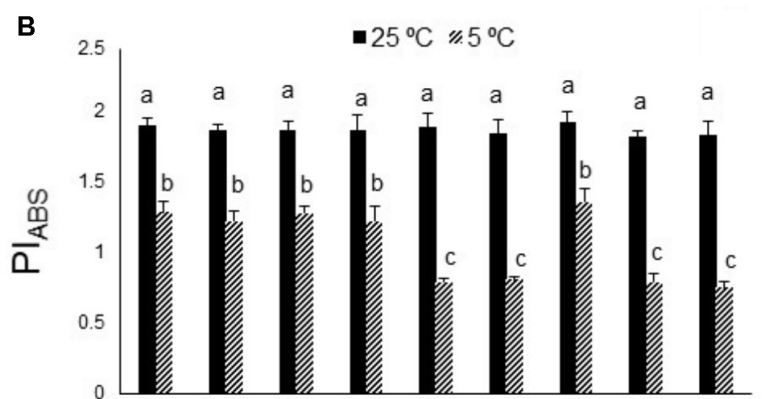

D

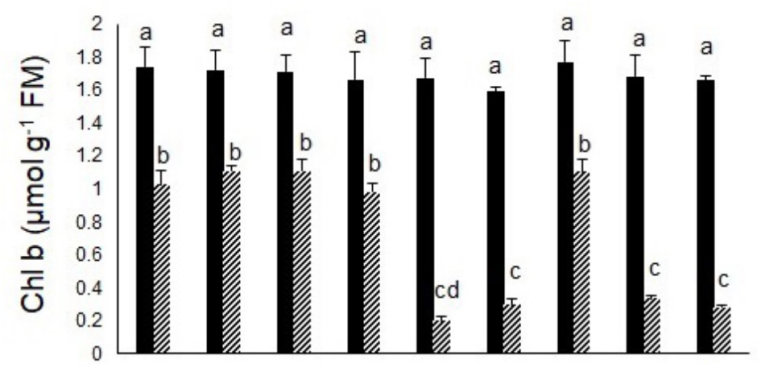

$\mathbf{F}$

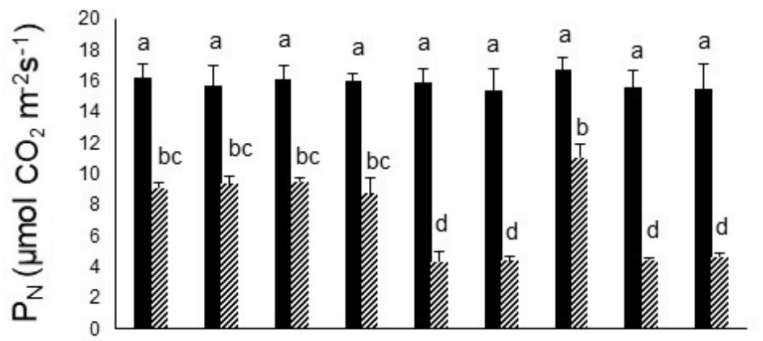

H

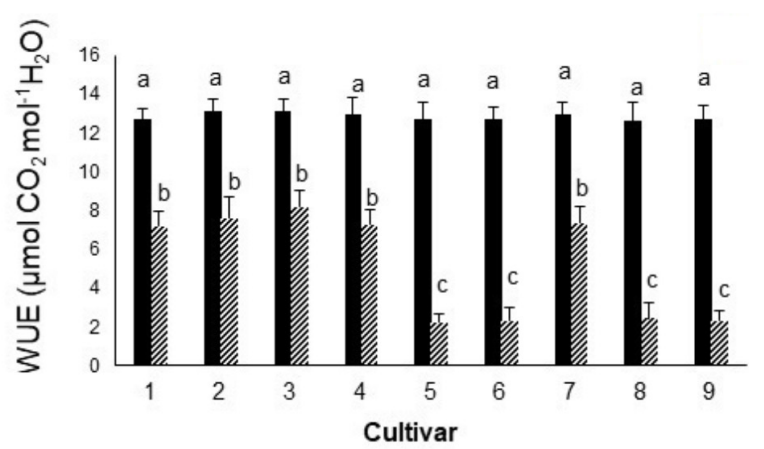

FIGURE 1 | (A) The maximum quantum yield of photosystem II ( $\left.F_{\mathrm{v}} / \mathrm{F}_{\mathrm{m}}\right)$, (B) performance index (PI $\left.\mathrm{ABS}\right),(\mathbf{C})$ chlorophyll a (Chl a), (D) chlorophyll $b(\mathrm{Chl} b)$, (E) carotenoids (car), (F) net photosynthesis $\left(\mathrm{P}_{\mathrm{N}}\right),(\mathbf{G})$ intercellular $\mathrm{CO}_{2}\left(\mathrm{C}_{\mathrm{i}}\right)$, and $\mathbf{( H )}$ water use efficiency (WUE) in nine cultivars of $S$. rebaudiana exposed to cold stress $\left(5^{\circ} \mathrm{C}\right)$ relative to the controls $\left(25^{\circ} \mathrm{C}\right)$. The experiment comprised a set of four jars in triplicate for each treatment. Two-way ANOVA was used to determine statistical differences. The means are the average of 12 plants. Columns with the same lower-case letters do not differ significantly at $p<0.05$; error bars represent standard deviation.

Photosynthetic pigments (Chl $a, \mathrm{Chl} b$, carotenoids) also declined with cold stress, more so in cultivars 5, 6, 8, and 9 than cultivars 1 , $2,3,4$, and 7 (Figures 1C-E). Cold stress significantly reduced $\mathrm{P}_{\mathrm{N}}$ by $81-84 \%$ in cultivars $5,6,8$, and 9 and by $46-57 \%$ in cultivars $1,2,3,4$, and 7, relative to the controls (Figure 1F). Cold stress significantly reduced the intracellular $\mathrm{CO}_{2}\left(\mathrm{C}_{\mathrm{i}}\right)$ concentration
(Figure 1G) and WUE (Figure 1H), with similar reductions in $\mathrm{P}_{\mathrm{N}}, \mathrm{PI}_{\mathrm{ABS}}$, photosynthetic pigments, and $\mathrm{F}_{\mathrm{v}} / \mathrm{F}_{\mathrm{m}}$ value in each cultivar.

In contrast to photosynthetic traits, the amounts of WSC and glucose increased significantly in all cultivars in response to cold stress (Figures 2A,B), more so in cultivars 5, 6, 8, and 9 (by 
$\sim 300-400 \%$ ) than cultivars 1, 2, 3, 4, and 7 (by $\sim 100-200 \%$ ). Cold stress caused morphological and anatomical changes in the stomata of leaves and stems of Stevia plants (Figures 3, 5); cultivars 2 and 5 had the highest and lowest stomatal number (72 vs. 7), stomatal density (186 vs. 19), and stomatal index (22 vs. 3 ), respectively (Figures 4 A-C). Cold stress significantly increased stomatal length in all cultivars, relative to the controls, while stomatal width increased in cultivars $3,4,6,7,8$, and 9 (Figures 4D,E). Cold stress increased epidermal cell size, thus reducing $\mathrm{ECD}$, with the highest and lowest reductions in cultivars 4 and 5 , being $\sim 77$ and $8 \%$ less than that in their control plants, respectively (Figure 4F).

Stem cross-sections differed between cold-stressed and control plants in all Stevia cultivars (Figure 5). Cold stress significantly increased stem diameter and thickness of epidermal, dermal, and xylematic vessel and phloem areas in all cultivars (Figures 6AD,G). The control plants of cultivars 1, 2, 6, 8, and 9 had few sclerenchyma colonies; cold stress promoted sclerenchyma colony production in all cultivars (Figure 6E) and increased the thickness of sclerenchyma (Figure 6F). Leaf fresh mass increased significantly in all cultivars in response to cold stress, by about $34,35,33,35,45,48,30,55$, and $54 \%$ in cultivars 1 through 9, respectively (Figure $\mathbf{6 H}$ ). The leaf area of six fully expanded leaves increased significantly in all cultivars under cold stress, by about $28,30,27,32,55,61,33,58$, and $60 \%$ in cultivars 1 through 9 , respectively (Figure 6I). Cold stress significantly increased the fresh mass of six leaves in all cultivars with the highest increase in cultivars $5,6,8$, and 9 , by about $76,80,81$, and $81 \%$, respectively (Figure 6J).

\section{DISCUSSION}

In recent years, much attention has been given to changes in photosynthetic traits in response to stress. The $F_{v} / F_{m}$ value is a reliable indicator of plant adaptation to stress (Sharma et al., 2012). Chlorophyll fluorescence emission was used by Mishra et al. (2011) to classify cold tolerance in nine Arabidopsis thaliana accessions. In this study, an initial screening measured the $\mathrm{F}_{\mathrm{v}} / \mathrm{F}_{\mathrm{m}}$ value and $\mathrm{PI}_{\mathrm{ABS}}$ in nine cultivars of $S$. rebaudiana from the EUSTAS Stevia Gene Bank (accessions 1-9) exposed to cold stress. The $\mathrm{F}_{\mathrm{v}} / \mathrm{F}_{\mathrm{m}}$ values declined in all nine cultivars in response to cold stress, and the magnitude of the reduction was genotype-dependent, being greater in cultivars 5, 6, 8, and 9 than cultivars 1,2, 3, 4, and 7. Soufi et al. (2016) also reported significant reductions in the $F_{v} / F_{m}$ value in Stevia plants under cold stress, which may be a protective mechanism of dissipating excitation energy in the PSII antennae as heat (Krause and Laasch, 1987; Adams et al., 2013, 2014) or damage to the Dl protein of PSII reaction centers responsible for photoinhibition (Groom and Baker, 1992; Adams et al., 2013). The $\mathrm{PI}_{\mathrm{ABS}}$ value provides quantitative information on the current state of plant performance under unfavorable conditions (Strasser et al., 2004). In the current study, the $\mathrm{PI}_{\mathrm{ABS}}$ value declined significantly in the nine Stevia cultivars in response to low temperature, more so in cultivars 5, 6, 8, and 9 than cultivars 1, 2, 3, 4, and 7. Fan et al. (2015) reported lower $\mathrm{PI}_{\mathrm{ABS}}$ values in cold-stressed Bermudagrass than the control. Adams et al. (2013) revealed that a reduction in photosynthesis might reflect photoinhibition (indicated by a reduction in $\mathrm{F}_{\mathrm{v}} / \mathrm{F}_{\mathrm{m}}$ and/or reduction in $\mathrm{CO}_{2}$ uptake or $\mathrm{O}_{2}$ evolution) to prevent photodamage in plants exposed to unfavorable conditions such as high light or low temperature. The decline in $\mathrm{PI}_{\mathrm{ABS}}$ and $\mathrm{F}_{\mathrm{v}} / \mathrm{F}_{\mathrm{m}}$ values in stressed Stevia plants suggests that the cold stress induced photoinhibition in all cultivars for plant survival and to prevent photodamage or damage to photosynthetic apparatus. Further measurements of photosynthetic pigments, photosynthesis, and carbohydrates provided more evidence for the downregulation of photosynthesis in response to cold stress.

We measured Chl $a$, Chl $b$, and carotenoid contents to characterize the correlation between the quantum efficiency of the photosystems and photosynthetic pigments in the reaction centers; all of which declined significantly under cold stress, more so in cultivars $5,6,8$, and 9 , and is in accordance with reports on rice (Han et al., 2017). In response to cold stress, Chl $a$ and $b$ contents declined the most in cultivars 9 and 5 , by $\sim 84$
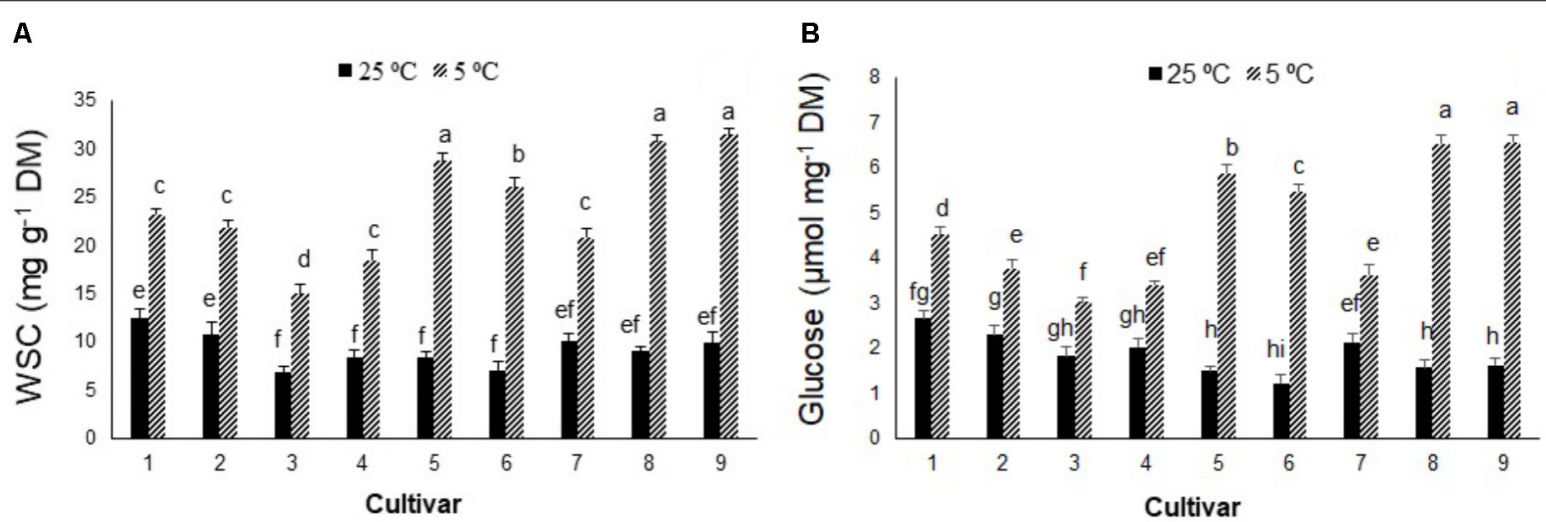

FIGURE 2 | (A) Water-soluble carbohydrates (WSC) and (B) glucose contents in nine cultivars of S. rebaudiana exposed to cold stress $\left(5^{\circ} \mathrm{C}\right)$ relative to the controls $\left(25^{\circ} \mathrm{C}\right)$. The experiment comprised a set of four jars in triplicate for each treatment. Two-way ANOVA was used to determine statistical differences. The means are the average of 12 values. Columns with the same lower-case letters do not differ significantly at $p<0.05$; error bars represent standard deviation. 


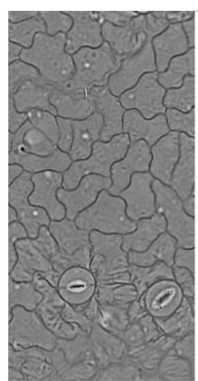

Control 1

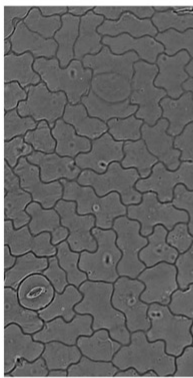

Control 4

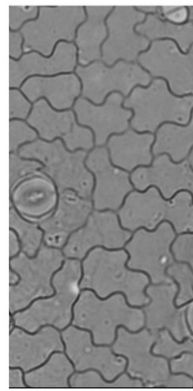

Control 7

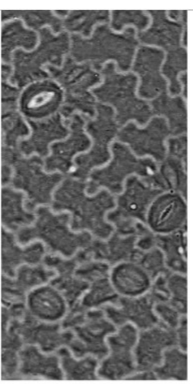

Cold 1

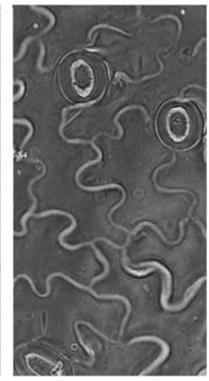

Cold 4

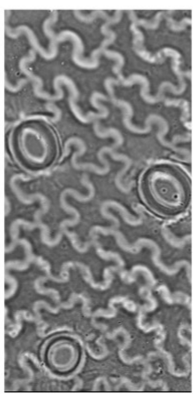

Cold 7

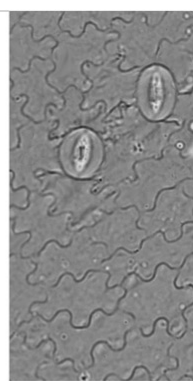

Control 2

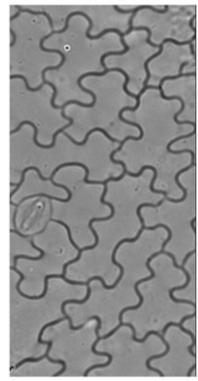

Control 5

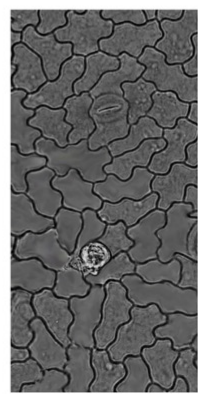

Control 8

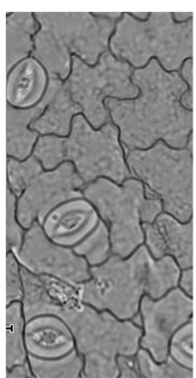

Cold 2

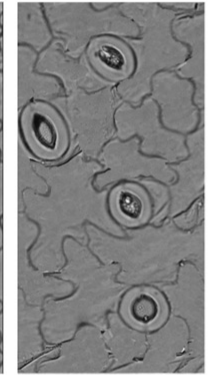

Cold 5

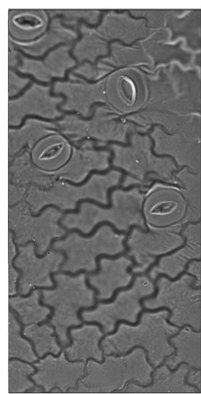

Cold 8

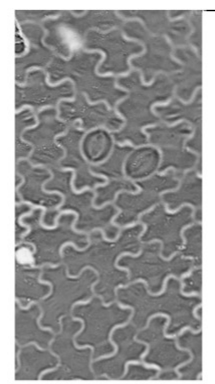

Control 3

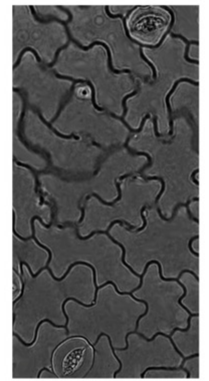

Control 6

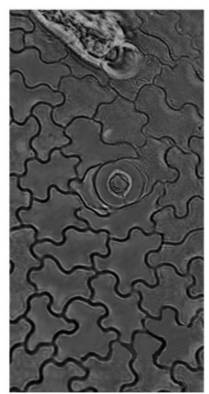

Control 9

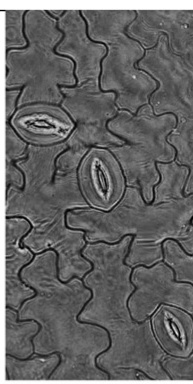

Cold 3

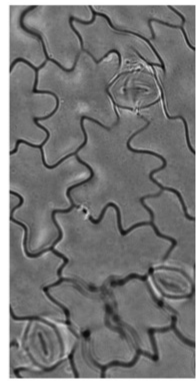

Cold 6

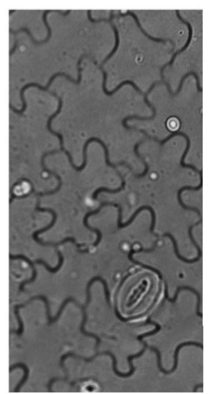

Cold 9

FIGURE 3 | Microphotographs of stomata on the adaxial leaf epidermis of nine cultivars of S. rebaudiana in control $\left(25^{\circ} \mathrm{C}\right)$ and cold-stressed $\left(5^{\circ} \mathrm{C}\right)$ plants.

and $\sim 88 \%$, respectively, relative to their controls. Carotenoid content declined the most in cultivar 5 , by $\sim 54 \%$ relative to its control. The smaller reduction in carotenoid content than Chl $a$ or $b$ content in response to cold stress may reflect the role of xanthophyll cycle carotenoids in releasing thermal energy and protecting PSII reaction centers (Demmig-Adams et al., 1996; Adams et al., 2006; Demmig-Adams and Adams, 2006). Tewari and Tripathy (1998) reported that a reduction in Chl biosynthesis in plants exposed to low-temperature stress is partially due to the inhibition of 5-aminolevulinic acid biosynthesis. In the current study, the reductions in Chl $a$, Chl $b$, and carotenoid contents in response to cold stress correlated well with the $\mathrm{F}_{\mathrm{v}} / \mathrm{F}_{\mathrm{m}}$ and $\mathrm{PI}_{\mathrm{ABS}}$ parameters. Several studies have demonstrated that low-temperature stress inhibits photosynthesis, as indicated by reductions in photosynthetic rate and pigment contents (Boese and Huner, 1990; Strand et al., 1997). A reduction in photosynthetic pigments reduces the level of light absorption and can be followed by a reduction in the level of excess excitation energy, as an alternative to increasing the level of energy dissipation, which lowers PSII efficiency (Demmig-Adams and Adams, 2006). In the nine Stevia cultivars, the reduction in light absorption and increase in energy dissipation seem to be acting concomitantly. Adams et al. (2002) reported that mesophytic species tend to upregulate photosynthetic capacity and increase chlorophyll levels in winter, while several evergreens and conifers tend to upregulate photoprotection and retain chlorophyll, which relies more on higher levels of energy dissipation.

A widely used method for studying plant photosynthesis is $\mathrm{P}_{\mathrm{N}}$ analysis. Winter annual species exhibited higher photosynthetic rates than summer annual species under cool temperatures (Adams et al., 2013; Demmig-Adams and Adams, 2018). The downregulation of photosynthesis and reduction in $\mathrm{P}_{\mathrm{N}}$ in the nine Stevia cultivars in response to low-temperature conditions is related to the observed reduction in chlorophyll fluorescence. Cold stress significantly reduced $\mathrm{P}_{\mathrm{N}}$, more so in cultivars $5,6,8$, and 9 than cultivars $1,2,3,4$, and 7 , which could be related to 


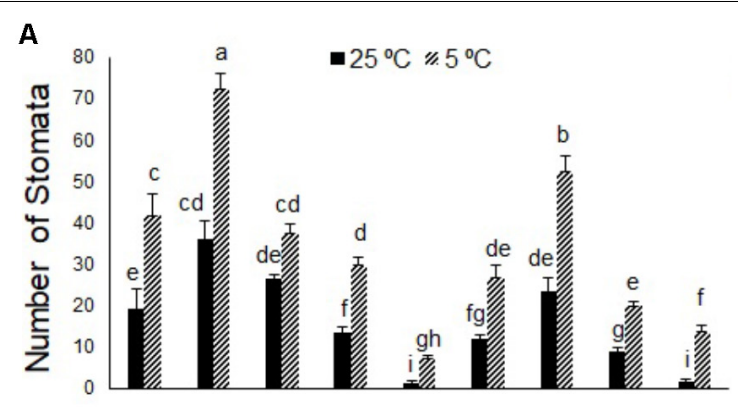

C

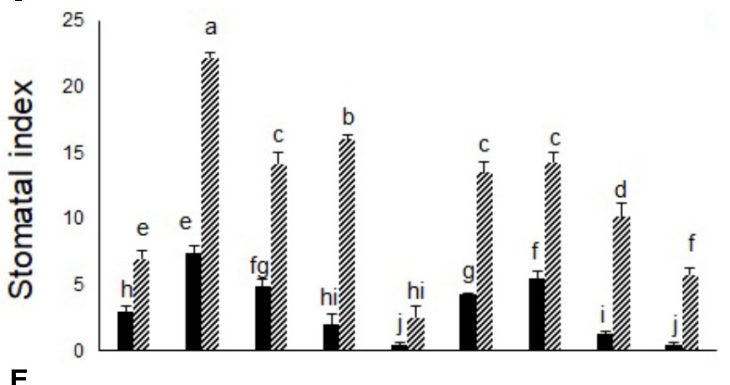

E

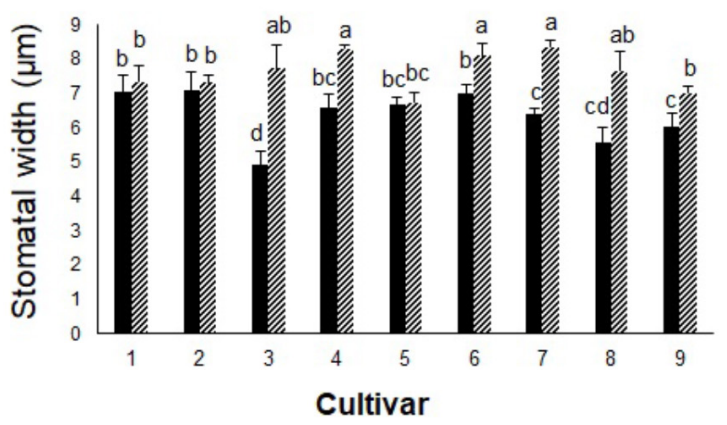

B

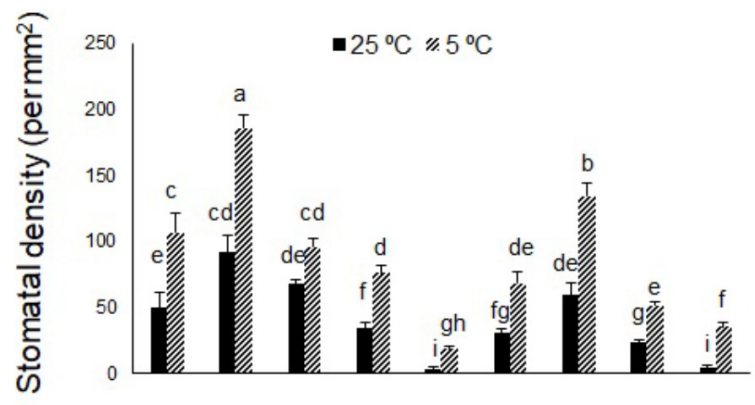

D

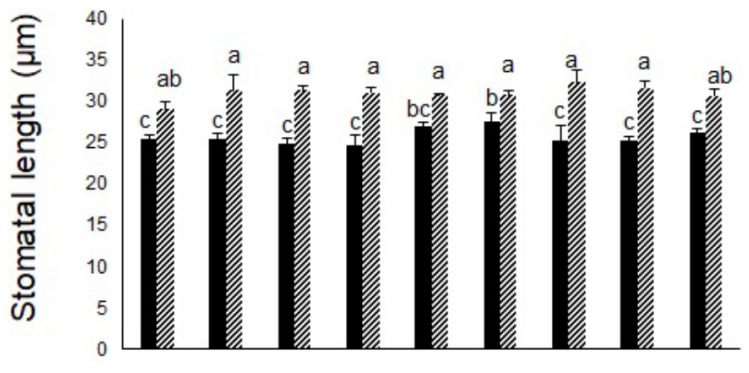

$\mathbf{F}$

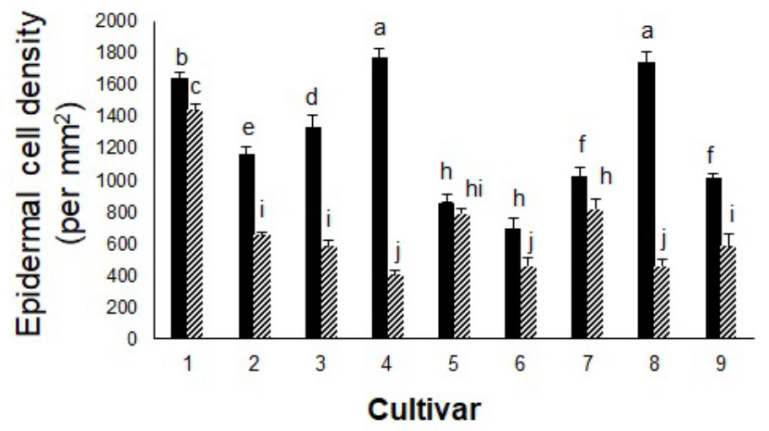

FIGURE 4 | (A) Stomatal number, (B) stomatal density, (C) stomatal index, (D) stomatal length, (E) stomatal width, and (F) epidermal cell index in nine cultivars of S. rebaudiana exposed to cold stress $\left(5^{\circ} \mathrm{C}\right)$ relative to the controls $\left(25^{\circ} \mathrm{C}\right)$. The experiment comprised a set of four jars for each treatment. Two-way ANOVA was used to determine statistical differences. The means are the average of four values. Columns with the same lower-case letters do not differ significantly at $p<0.05$; error bars represent standard deviation.

changes in fluorescence. Photoinhibition can be characterized as a decrease in photosynthetic $\mathrm{CO}_{2}$ uptake (Adams et al., 2013). In the present study, the $\mathrm{CO}_{2}$ concentration declined significantly in response to cold stress, which was more pronounced in cultivars $5,6,8$, and 9 than cultivars $1,2,3,4,7$.

The D1 protein of the PSII reaction center is involved in water oxidation to provide electrons for PSI. Photoinactivation or photodamage of the D1 protein during photoinhibition is a mechanism responsible for photoprotection (Adams et al., 2006, 2013). Damage to the D1 protein and oxygen-evolving complex is followed by a reduction in water oxidation (Adams et al., 2013). A decline in water status in response to cold stress may play an indirect role by reducing the capacity for gas exchange. In our study, the WUE of Stevia leaves declined significantly at $5^{\circ} \mathrm{C}$, more so in cultivars $5,6,8$, and 9 than cultivars 1,2 , 3,4 , and 7 . The reduction in leaf water status was linked to lower $\mathrm{CO}_{2}$ concentrations and a reduction in photosynthesis. Often, increases in intercellular $\mathrm{CO}_{2}$ concentration are beneficial for photosynthesis, while decreases suggest inhibition of the photosynthetic apparatus. Zhu et al. (2018) reported that $\mathrm{CO}_{2}$ elevation enhanced the efficiency of photosynthetic electron transport in cold-stressed wheat plants. Thus, in our study, the reduction in gas exchange capacity of the Stevia plants exposed to cold stress was likely followed by a reduction in $\mathrm{P}_{\mathrm{N}}$, which supports the findings of Soufi et al. (2016) that cold stress had a negative effect on photosynthesis in Stevia plants.

The light energy absorbed by Chl molecules can be used in photosynthesis (sugar biosynthesis), dissipated as heat, or re-emitted as Chl fluorescence (Maxwell and Johnson, 2000). Sugar synthesis occurs in a plant's mature source leaves, which is then exported to the sinks (e.g., young leaves, fruits) (Adams et al., 2014). Despite the decline in $\mathrm{F}_{\mathrm{v}} / \mathrm{F}_{\mathrm{m}}$ values and corresponding reductions in $\mathrm{P}_{\mathrm{N}}$, cold stress increased carbohydrate and glucose accumulation in the nine Stevia cultivars, particularly cultivars 5, 6, 8, and 9. Previous reports have shown that low temperatures increase soluble sugars in 


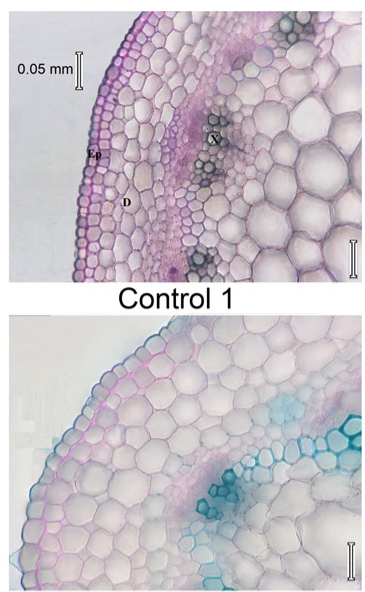

Control 3

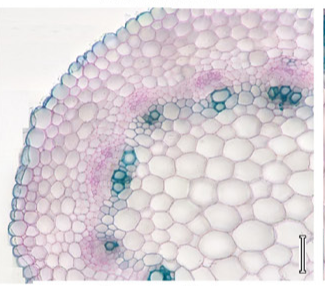

Control 5

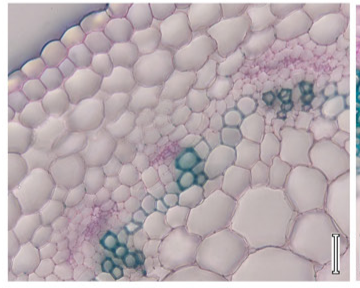

Control 7

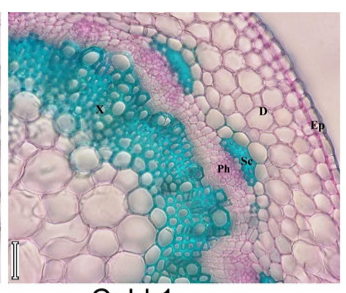

Cold 1

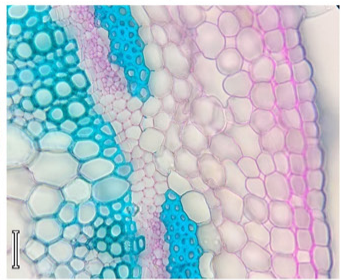

Cold 3

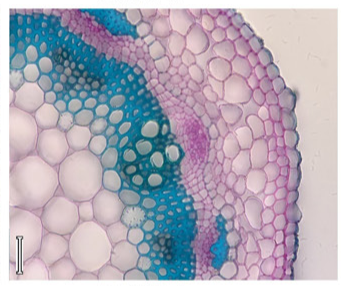

Cold 5

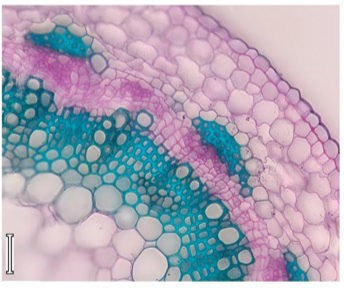

Cold 7

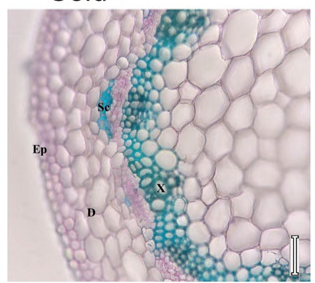

Control 9

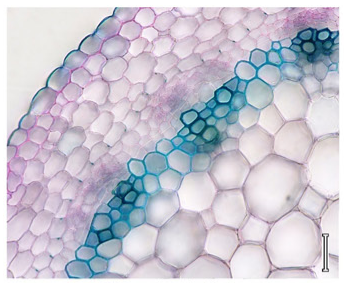

Control 2

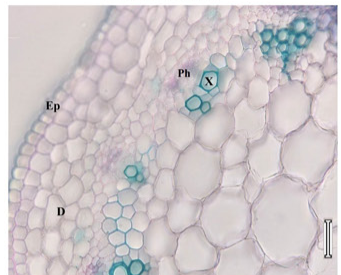

Control 4

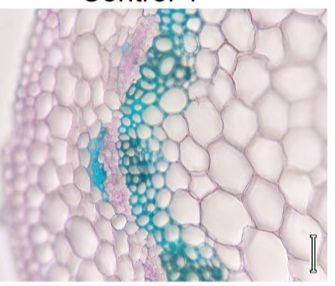

Control 6

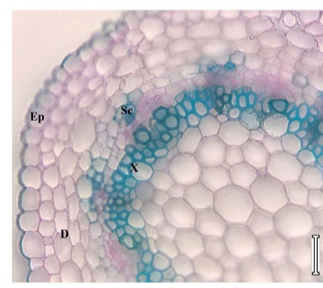

Control 8

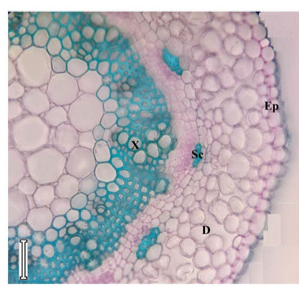

Cold 9

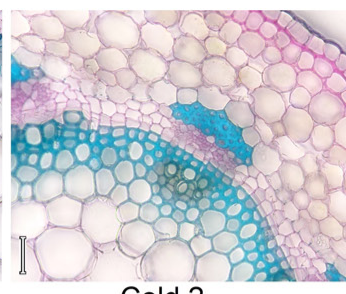

Cold 2

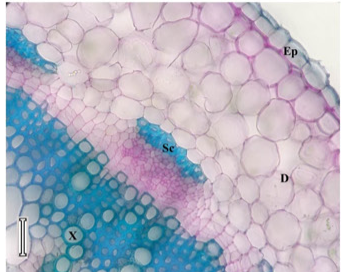

Cold 4

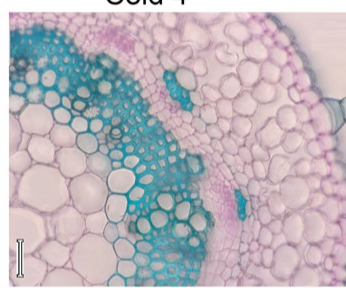

Cold 6

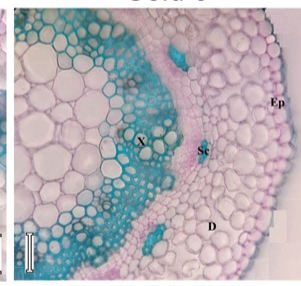

Cold 8

FIGURE 5 | Micrograph of stem cross section in nine cultivars of S. rebaudiana in control $\left(25^{\circ} \mathrm{C}\right)$ and cold-stressed $\left(5^{\circ} \mathrm{C}\right)$ plants. D, Derma; Ep, epiderma; Sc, sclerenchyma; $X$, xylem vessel.

the leaves of different plants (Strand et al., 1997; Adams et al., 2013, 2014). Modifications to carbohydrate metabolism could be induced by altering the balance between source and sink organs (Adams et al., 2013, 2014; Lemoine et al., 2013). Plants accumulate sugars in source leaves when production exceeds the rate of export (Adams et al., 2013, 2014). Adams et al. (2014) suggested that carbohydrate accumulation in photoinhibited leaves under stress conditions may lead to feedback inhibition, downregulation of photosynthesis, or inhibition of foliar export of carbohydrates. The movement of liquid water out of cells and increased osmotic concentration inside cells prevent intracellular freezing (Ameglio et al., 2001). In wheat, cold stress enhanced leaf vacuolar carbon storage through increased fructans accumulation and the polymerization of sucrose to fructans in the crown tissues (Leonardos et al., 2003). Furthermore, increased amounts of carbohydrate and the subsequent reduction in osmotic potential have been observed in cold-stressed $\left(5^{\circ} \mathrm{C}\right)$ wheat plants (Equiza et al., 2001). A linear correlation between carbohydrate accumulation and SVglys levels has been reported in the leaves of S. rebaudiana (Ceunen and Geuns, 2013), so the higher glucose content in cold-stressed Stevia cultivars may be correlated with higher SVglys biosynthesis.

In addition to the increased carbohydrate contents in the nine Stevia cultivars, the amount of phloem tissue in the stem 


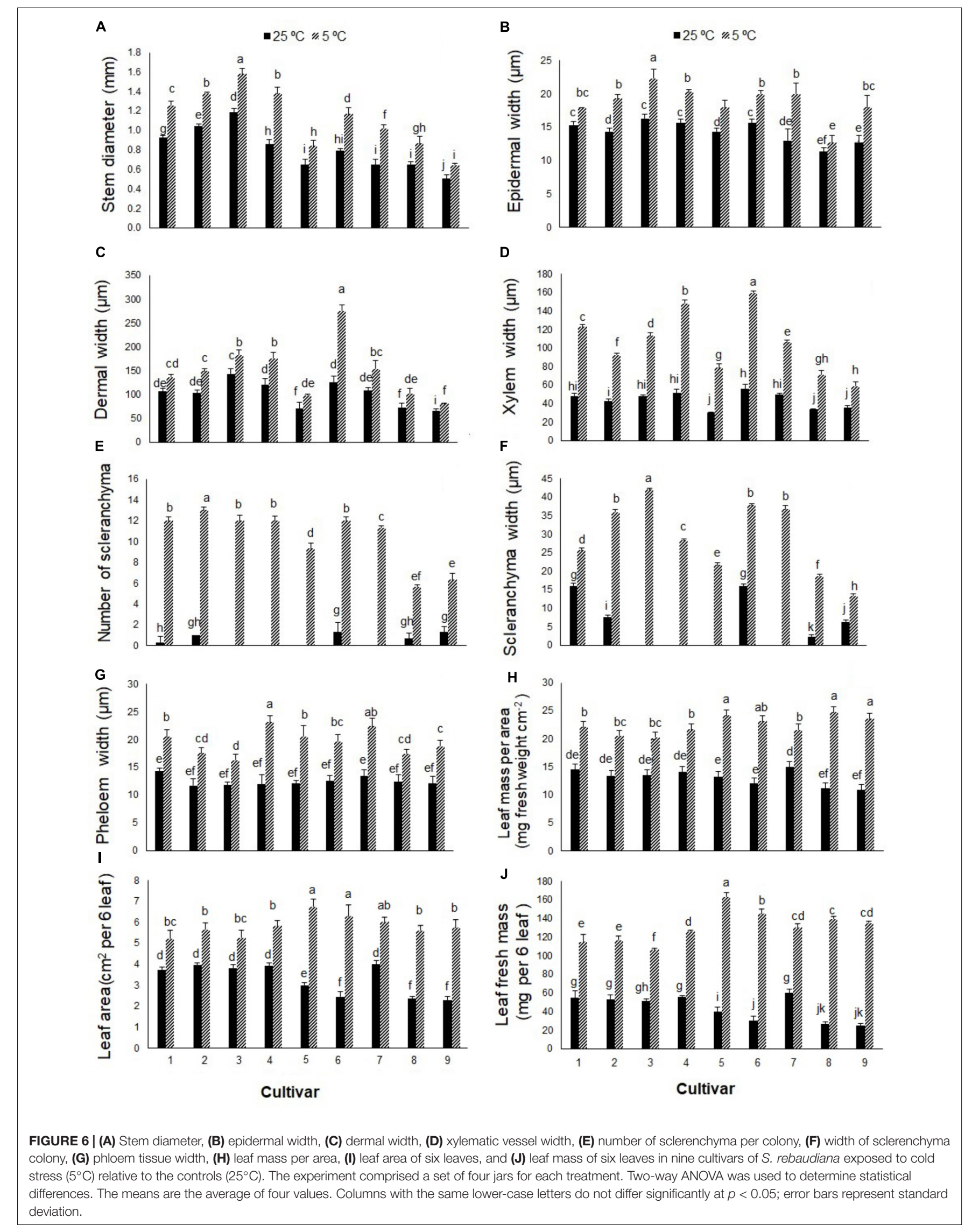


increased significantly in response to cold stress, which may be needed to export the greater volume of carbohydrates produced in leaves to the rest of the plant. Similarly, Cohu et al. (2014) reported a significant increase in sugar content and phloem tissue in the leaf veins of Spinacia oleracea and A. thaliana in response to cool temperatures. Furthermore, the higher leaf mass per unit area in response to cold stress may reflect increased cell wall, as reported by Domon et al. (2013) in Miscanthus ecotypes. Stevia leaves are used as a natural sweetener (Geuns, 2003), so higher leaf mass and carbohydrate contents in cold-stressed Stevia cultivars can reflect higher yields at low temperature. S. rebaudiana originated in Paraguay with an optimum growth temperature of $24^{\circ} \mathrm{C}$ (Ahmed et al., 2011), yet all nine cultivars of Stevia in this study produced more leaf mass and area under cold stress. Cold stress increased fresh leaf mass, carbohydrate contents, phloem tissue, and stem diameters in the nine Stevia cultivars regardless of the observed reductions in photosynthetic capacity, which possibly reflects plant adjustment to cold stress.

There are reports on the effect of cold stress on stomatal apparatus and epidermal cells (Boese and Huner, 1990; Ameglio et al., 2001). In the present study, cold stress significantly affected leaf and stem anatomy in the Stevia cultivars, increasing the stomatal number, size, density, and index, and decreasing ECD. In spinach, stomatal number and ECD did not change when exposed to low temperature $\left(5^{\circ} \mathrm{C}\right)$ stress (Boese and Huner, 1990). In Stevia, the increase in stomatal index and density could increase water loss and reduce leaf water potential, which may explain the observed reductions in WUE, $\mathrm{C}_{\mathrm{i}}$, and $\mathrm{P}_{\mathrm{N}}$ in the nine tested cultivars. Some plants exhibit low leaf water potentials in response to chilling stress, which may limit photosynthetic activity (Pardossi et al., 1992; Wilkinson et al., 2001). Cold stress increased the width of derma, epiderma, xylem, phloem, and sclerenchyma, which was followed by an increase in stem diameter in all Stevia cultivars. Equiza et al. (2001) suggested that increased epidermal thickness in response to cold stress is an adaptive reaction to increase freezing tolerance. Sclerenchyma is one of the main supporting tissues of growing plant organs (Leroux, 2012); its increase in response to cold stress may have increased stem hardness in the Stevia cultivars. The increase in xylem vessels in response to cold stress may increase water transport from roots to leaves to prevent reductions in water potential. The diameter and frequency of xylem vessels are critical determinants of water conductance (Lovisolo and Schubert, 1998).

\section{REFERENCES}

Adams, W. W., and Demmig-Adams, B. (2004). "Chlorophyll fluorescence as a tool to monitor plant response to the environment," in Chlorophyll a Fluorescence: A Signature of Photosynthesis, Advances in Photosynthesis and Respiration, Vol. 19, eds G. C. Papageorgiou and Govindjee (Dordrecht: Springer), 583-604.

Adams, W. W., Demmig-Adams, B., Rosenstiel, T. N., Brightwell, A. K., and Ebbert, V. (2002). Photosynthesis and photoprotection in overwintering plants. Plant Biol. 4, 545-557. doi: 10.1055/s-2002-35434

Adams, W. W., Muller, O., Cohu, C. M., and Demmig-Adams, B. (2013). May photoinhibition be a consequence, rather than a cause, of limited plant productivity? Photosynth. Res. 117, 31-44. doi: 10.1007/s11120-013-9849-7

\section{CONCLUSION}

Cold stress significantly reduced the measured photosynthetic traits $-\mathrm{F}_{\mathrm{v}} / \mathrm{F}_{\mathrm{m}}, \mathrm{PI}_{\mathrm{ABS}}, \mathrm{P}_{\mathrm{N}}, \mathrm{WUE}, \mathrm{C}_{\mathrm{i}}$, and $\mathrm{Chl} a$, Chl $b$, and carotenoid contents - in Stevia cultivars, but the impact was more evident in cultivars 5, 6, 8, and 9 than cultivars $1,2,3,4$, and 7 . The degree of reduction in the measured traits was related to genotype. Regardless of the observed reduction in photosynthetic capacity, the carbohydrate content and leaf mass and area increased, more so in cultivars 5, 6, 8, and 9. These results suggest downregulation of photosynthetic activity by photoinhibition to increase photoprotection of the photosynthetic apparatus. Even though all Stevia cultivars exhibited photoinhibition under cold stress, the higher carbohydrate accumulation and leaf mass produced at $5^{\circ} \mathrm{C}$, compared to $25^{\circ} \mathrm{C}$, suggests no critical damage of photosystems being responsible for the reduction in chlorophyll fluorescence and photosynthesis. Measuring SVglys content, a critical characteristic of $S$. rebaudiana cultivars, to identify their absolute yield in regions with cold winters. Furthermore, the upregulation of anatomical features in Stevia plants may contribute to the success of all cultivars under cold stress. In future, more detailed measurements - including photosynthetic parameters (non-photochemical quenching, zeaxanthin, D1 protein, transpiration), reactive oxygen species, antioxidant system, quantitative analyses of responsible genes in SVglys biosynthesis, carbohydrate metabolism, and sugar exudation could help to determine how plants contribute to cold stress. Furthermore, a complementary study on the lethal temperature 50 (LT50) of plants and their performance after the transition of cold-stressed Stevia cultivars to warmer temperatures would help to identify more cold-adapted cultivars.

\section{AUTHOR CONTRIBUTIONS}

SH, FN, JG, ID, and KS designed the research and wrote the manuscript. SH did the experiments and analyzed the results. SH and FN did the anatomical experiments. JG provided the plants.

\section{ACKNOWLEDGMENTS}

We thank Prof. William Adams for critical comments on an early version of the manuscript.

Adams, W. W., Muller, O., Cohu, C. M., and Demmig-Adams, B. (2014). "Photosystem II efficiency and non-photochemical quenching in the context of source-sink balance," in Non-Photochemical Quenching and Energy Dissipation in Plants, Algae and Cyanobacteria, Advances in Photosynthesis and Respiration, Vol. 40, eds B. Demmig-Adams, G. Garab, W. W. Adams, and Govindjee (Dordrecht: Springer), 503-529.

Adams, W. W., Stewart, J. J., Cohu, C. M., Muller, O., and Demmig-Adams, B. (2016). Habitat temperature and precipitation of Arabidopsis thaliana ecotypes determine the response of foliar vasculature, photosynthesis, and transpiration to growth temperature. Front. Plant Sci. 7:1026. doi: 10.3389/fpls.2016.01026

Adams, W. W., Zarter, C. R., Mueh, K. E., Amiard, V., and DemmigAdams, B. (2006). "Energy dissipation and photoinhibition: a continuum of 
photoprotection," in Photoprotection, Photoinhibition, Gene Regulation, and Environment, Advances in Photosynthesis and Respiration, Vol. 21, eds B. Demmig-Adams, W. W. Adams, and A. K. Mattoo (Dordrecht: Springer), 49-64. doi: 10.1007/1-4020-3579-9_5

Ahmed, B., Hossain, M., Islam, R., Kumar Saha, A., and Mandal, A. (2011). A review on natural sweetener plant-Stevia having medicinal and commercial importance. Agronomski glasnik: Glasilo Hrvatskog agronomskog društva 73, 75-91.

Ameglio, T., Cochard, H., and Ewers, F. W. (2001). Stem diameter variation and cold hardiness in walnut trees. J. Exp. Bot. 52, 2135-2142. doi: 10.1093/jexbot/ 52.364.2135

Amini Rad, M., and Sonboli, A. (2008). Leaf and stem anatomy of the cyperus subgenus cyperus in Iran. Rostaniha 9, 6-22.

Banon, S., Fernandez, J. A., Franco, J. A., Torrecillas, A., Alarcón, J. J., and Sánchez-Blanco, M. J. (2004). Effects of water stress and night temperature preconditioning on water relations and morphological and anatomical changes of Lotus creticus plants. Sci. Hortic. 101, 333-342. doi: 10.1016/j.scienta.2003. 11.007

Boese, S. R., and Huner, N. P. A. (1990). Effect of growth temperature and temperature shifts on spinach leaf morphology and photosynthesis. Plant Physiol. 94, 1830-1836. doi: 10.1104/pp.94.4.1830

Ceunen, S., and Geuns, J. M. (2013). Steviol glycosides: chemical diversity, metabolism, and function. J. Nat. Prod. 76, 1201-1228. doi: 10.1021/np400203b

Cohu, C. M., Muller, O., Adams, W. W., and Demmig-Adams, B. (2014). Leaf anatomical and photosynthetic acclimation to cool temperature and high light in two winter versus two summer annuals. Physiol. Plant. 152, 164-173. doi: $10.1111 / \mathrm{ppl} .12154$

Demmig-Adams, B., and Adams, W. W. (2006). Photoprotection in an ecological context: the remarkable complexity of thermal energy dissipation. New Phytol. 172, 11-21. doi: 10.1111/j.1469-8137.2006.01835.x

Demmig-Adams, B., and Adams, W. W. (2018). An integrative approach to photoinhibition and photoprotection. Environ. Exp. Bot. 154, 1-3. doi: 10.1016/ j.envexpbot.2018.05.006

Demmig-Adams, B., Gilmore, A. M., and Adams, W. W. (1996). In vivo functions of carotenoids in higher plants. FASEB J. 10, 403-412. doi: 10.1096/fasebj.10.4. 8647339

Domon, J. M., Baldwin, L., Acket, S., Caudeville, E., Arnoult, S., Zub, H., et al. (2013). Cell wall compositional modifications of Miscanthus ecotypes in response to cold acclimation. Phytochemistry 85, 51-61. doi: 10.1016/j. phytochem.2012.09.001

Dubois, M., Gilles, K. A., Hamilton, J. K., Reberts, P. A., and Smith, F. (1956). Colorimetric method for determination of sugar and related substrates. Anal. Chem. 28, 350-356. doi: 10.1186/1479-5876-9-103

Ensminger, I., Busch, F., and Huner, N. P. A. (2006). Photostasis and cold acclimation: sensing low temperature through photosynthesis. Physiol. Plant. 126, 28-44. doi: 10.3389/fpls.2012.00255

Equiza, M. A., Miravea, J. P., and Tognetti, J. A. (2001). Morphological, anatomical and physiological responses related to differential shoot vs. root growth inhibition at low temperature in spring and winter wheat. Ann. Bot. 87, 67-76. doi: 10.1006/anbo.2000.1301

Fan, J., Hu, Z., Xie, Y., Chan, Z., Chen, K., Amombo, E., et al. (2015). Alleviation of cold damage to photosystem II and metabolisms by melatonin in Bermudagrass. Front. Plant Sci. 6:925. doi: 10.3389/fpls.2015.00925

Franks, P. J., and Farquhar, G. D. (2007). The mechanical diversity of stomata and its significant in gas-exchange control. Plant Physiol. 143, 78-87. doi: 10.1104/ pp.106.089367

Geuns, J. M. (2003). Stevioside. Phytochemistry 64, 913-921. doi: 10.1016/S00319422(03)00426-6

Groom, Q. J., and Baker, N. R. (1992). Analysis of light-induced depressions of photosynthesis in leaves of a wheat crop during the winter. Plant Physiol. 100, 1217-1223. doi: 10.1104/pp.100.3.1217

Han, Q. H., Huang, B., Ding, C. B., Zhang, Z. W., Chen, Y. E., Hu, C., et al. (2017). Effect of melatonin on anti-oxidative systems and photosystem II in cold-stressed rice seedlings. Front. Plant Sci. 8:785. doi: 10.3389/fpls.2017.00785

Hill, K. E., Guerin, G. R., Hill, R. S., and Watling, J. R. (2014). Temperature influences stomatal density and maximum potential water loss through stomata of Dodonaea viscosa subsp. Angustissima along a latitude gradient in southern Australia. Aust. J. Bot. 62, 657-665. doi: 10.1071/BT14204
Krause, G. H., and Laasch, H. (1987). "Photoinhibition of photosynthesis. Studies on mechanisms of damage and protection in chloroplasts," in Progress in Photosynthesis Research, Vol. 4, ed. J. Biggins (Dordrecht: Martinus Nijhoff Publishers), 19-26.

Kumar Yadav, S. (2010). Cold stress tolerance mechanisms in plants. A review. Agron. Sustain. Dev. 30, 515-527. doi: 10.1051/agro/2009050

Lemoine, R., Camera, S. L., Atanassova, R., Dédaldéchamp, F., Allario, T., Pourtau, N., et al. (2013). Source-to-sink transport of sugar and regulation by environmental factors. Front. Plant Sci. 4:272. doi: 10.3389/fpls.2013.00272

Leonardos, E. D., Savitch, L. V., Huner, N. P. A., Oquist, G., and Grodzinski, B. (2003). Daily photosynthetic and C-export patterns in winter wheat leaves during cold stress and acclimation. Physiol. Plant. 117, 521-531. doi: 10.1034/j. 1399-3054.2003.00057.x

Leroux, O. (2012). Collenchyma: a versatile mechanical tissue with dynamic cell walls. Ann. Bot. 110, 1083-1098. doi: 10.1093/aob/mcs186

Lichtenthaler, H. K., and Wellburn, A. (1983). Determination of total carotenoids and chlorophylls a and b of leaf in extracts in different solvents. Biochem. Soc. Trans. 603, 591-592. doi: 10.1042/bst0110591

Logan, B. A., Adams, W. W., and Demmig-Adams, B. (2007). Avoiding common pitfalls of chlorophyll fluorescence analysis under field conditions. Funct. Plant Biol. 34, 853-859. doi: 10.1071/FP07113

Logan, B. A., Demmig-Adams, B., Adams, W. W., and Bilger, W. (2014). “Context, quantification, and measurement guide for non-photochemical quenching of chlorophyll fluorescence," in Non-Photochemical Quenching and Energy Dissipation in Plants, Algae and Cyanobacteria. Advances in Photosynthesis and Respiration, Vol. 40, eds B. Demmig-Adams, G. Garab, W. W. Adams, and Govindjee (Dordrecht: Springer), 187-201.

Lovisolo, C., and Schubert, A. (1998). Effects of water stress on vessel size and xylem hydraulic conductivity in Vitis vinifera L. J. Exp. Bot. 49, 693-700.

Maherali, H., Reid, C. D., Polley, H. W., Johnson, H. B., and Jachson, R. B. (2002). Stomatal acclimation over a subambient to elevated CO2 gradient in a C3/C4 grassland. Plant Cell Environ. 25, 557-566. doi: 10.1046/j.1365-3040. 2002.00832.x

Maxwell, K., and Johnson, G. N. (2000). Chlorophyll fluorescence-a practical guide. J. Exp. Bot. 51, 659-668. doi: 10.1093/jexbot/51.345.659

Mishra, A., Mishra, K. B., Höermiller, I. I., Heyer, A. G., and Nedbal, L. (2011). Chlorophyll fluorescence emission as a reporter on cold tolerance in Arabidopsis thaliana accessions. Plant Signal. Behav. 6, 301-310. doi: 10.4161/ psb.6.2.15278

Muller, O., Stewart, J. J., Cohu, C. M., Polutchko, S. K., Demmig-Adams, B., and Adams, W. W. (2014). Leaf architectural, vascular, and photosynthetic acclimation to temperature in two biennials. Physiol. Plant 152, 763-772. doi: $10.1111 / \mathrm{ppl} .12226$

Murashige, T., and Skoog, F. (1962). A revised medium for rapid growth and bioassays with tobacco tissue cultures. Physiol. Plant. 15, 473-479. doi: 10.1111/ j.1399-3054.1962.tb08052.x

Pardossi, A., Vernieri, P., and Tognoni, F. (1992). Involvement of abscisic acid in regulating water status in Phaseolus vulgaris L. during chilling. Plant Physiol. 100, 1243-1250. doi: 10.1104/pp.100.3.1243

Psaras, G. K., and Sofroniou, I. (2004). Stem and root wood anatomy of the shrub Phlomis fruticosa (Labiatae). IAWA J. 1, 71-77. doi: 10.1163/2294193290000350

Royer, D. L. (2001). Stomatal density and stomatal index as indicators of paleoatmospheric CO2 concentration. Rev. Palaeobot. Palynol. 114, 1-28. doi: 10.1016/S0034-6667(00)00074-9

Sharma, D. K., Andersen, S. B., Ottosen, C. O., and Rosenqvist, E. (2012). Phenotyping of wheat cultivars for heat tolerance using chlorophyll a fluorescence. Funct. Plant Biol. 39, 936-947. doi: 10.1071/FP12100

Soufi, S., D’Urso, G., Pizza, C., Rezgui, S., Bettieb, T., and Monotoro, P. (2016). Steviol glycosides targeted analysis in leaves of Stevia rebaudiana (Bertoni) from plants cultivated under chilling stress conditions. Food Chem. 190, 572-580. doi: 10.1016/j.foodchem.2015.05.116

Stewart, J. J., Demmig-Adams, B., Cohu, C. M., Wenzl, C. A., Muller, O., and Adams, W. W. (2016). Growth temperature impact on leaf form and function in Arabidopsis thaliana ecotypes from northern and southern Europe. Plant Cell Environ. 39, 1549-1558. doi: 10.1111/pce.12720

Strand, A., Hurry, V., Gustafsson, P., and Gardestrom, P. (1997). Development of Arabidopsis thaliana leaves at low temperatures releases the suppression of 
photosynthesis and photosynthetic gene expression despite the accumulation of soluble carbohydrates. Plant J. 12, 605-614. doi: 10.1046/j.1365-313X.1997. 00605.x

Strasser, R. J., Tsimilli-Michael, M., and Srivastava, A. (2004). "Analysis of the fluorescence transient," in Chlorophyll Fluorescence: A Signature of Photosynthesis. Advances in Photosynthesis and Respiration Series, eds G. C. Papageorgiou and Govindjee (Dordrecht: Springer), 321-362. doi: 10.1007/9781-4020-3218-9_12

Tewari, A. K., and Tripathy, B. C. (1998). Temperature-stress-induced impairment of chlorophyll biosynthetic reactions in cucumber and wheat. Plant Physiol. 117, 851-858. doi: 10.1104/pp.117. 3.851

Van den Houwe, I., André, E., Swennen, R., and Panis, B. (2011). "In vitro conservation and cryopreservation of banana: a model for Stevia?," in Stevia: Break-through in Europa, ed. J. M. C. Geuns (Heverlee: Euprint), 89-104.

Vezza, M. E., Llanes, A., Travaglia, C., Agostinia, E., and Talanoa, M. A. (2018). Arsenic stress effects on root water absorption in soybean plants: physiological and morphological aspects. Plant Physiol. Biochem. 123, 8-17. doi: 10.1016/j. plaphy.2017.11.020

Wilkinson, S., Clephan, A. L., and Davies, W. J. (2001). Rapid low temperatureinduced stomatal closure occurs in cold-tolerant Commelina communis L. leaves but not in cold-sensitive Nicotiana rustica L. leaves, via a mechanism that involves apoplastic calcium but not abscisic acid. Plant Physiol. 126, 1566-1578. doi: $10.1104 /$ pp.126.4.1566

Wu, G., Liu, H., Hua, L., Luo, Q., Lin, Y., He, P., et al. (2018). Differential responses of stomata and photosynthesis to elevated temperature in two co-occurring subtropical forest tree species. Front. Plant. Sci. 9:467. doi: 10.3389/fpls.2018. 00467
Xu, Z., Jiang, Y., Jia, B., and Zhou, G. (2016). Elevated-CO2 response of stomata and its dependence on environmental factors. Front. Plant Sci. 7:657. doi: 10. 3389/fpls.2016.00657

Yan, W., Zhong, Y., and Shangguan, Z. (2017). Contrasting responses of leaf stomatal characteristics to climate change: a considerable challenge to predict carbon and water cycles. Glob. Chang. Biol. 104, 145-157. doi: 10.1111/gcb. 13654

Zheng, Y., Xu, M., Hou, R., Shen, R., Qiu, S., and Ouyang, Z. (2013). Effects of experimental warming on stomatal traits in leaves of maize (Zea may L.). Ecol. Evol. 3, 3095-3111. doi: 10.1002/ece3.674

Zhu, X., Liu, S., Sun, L., Song, F., Liu, F., and Li, X. (2018). Cold tolerance of photosynthetic electron transport system is enhanced in wheat plants grown under elevated CO2. Front. Plant Sci. 9:933. doi: 10.3389/fpls.2018.00933

Živčák, M., Brestič, M., Olšovská, K., and Slamka, P. (2008). Performance index as a sensitive indicator of water stress in Triticum aestivum L. Plant Soil Environ. 54, 133-139. doi: 10.17221/392-PSE

Conflict of Interest Statement: The authors declare that the research was conducted in the absence of any commercial or financial relationships that could be construed as a potential conflict of interest.

Copyright (c) 2018 Hajihashemi, Noedoost, Geuns, Djalovic and Siddique. This is an open-access article distributed under the terms of the Creative Commons Attribution License (CC BY). The use, distribution or reproduction in other forums is permitted, provided the original author(s) and the copyright owner(s) are credited and that the original publication in this journal is cited, in accordance with accepted academic practice. No use, distribution or reproduction is permitted which does not comply with these terms. 